\title{
Orignal
}

\section{The Constant Extension Rate Tensile of AZ31B Magnesium Alloy with Si-contained Coating in Dynamic Simulated Body Fluid}

\author{
Qiang Wang ${ }^{1 *}$, Yoshinori Nakamura ${ }^{2)}$, Ikuro Kato ${ }^{3)}$, Hatsuhiko Maeda ${ }^{3)}$, Lili Tan ${ }^{4)}$ and Ke Yang $^{4)}$ \\ ${ }^{1)}$ School of Stomatology, China Medical University, Shenyang, China \\ 2) Department of Removable Prosthodontics, School of Dentistry, Aichi Gakuin University, Nagoya, Japan \\ 3) Department of Oral Pathology, School of Dentistry, Aichi Gakuin University, Nagoya, Japan \\ 4) Institute of Metal Research, Chinese Academy of Sciences, Shenyang, China \\ (Accepted for publication, February 18, 2013)
}

\begin{abstract}
The tensile fracture characteristics of AZ31B magnesium alloy with Si-contained coating was studied using a constant extension rate tensile in dynamic Hank's solution. The study showed that the fracture characteristics of the uncoated and coated AZ31B magnesium were different. The uncoated alloy exhibited predominant intergranular cracks while the coated revealed mixed intergranular and transgranular mode failure. The mechanical integrity of the coated AZ31B magnesium alloy was improved compared with the uncoated.
\end{abstract}

Key word: Magnesium alloys, Constant extension, Intergranular crack, Transgranular crack

\section{Introduction}

The development of bioresorbable bone implants has seen a great number of innovations in the past years ${ }^{1,2)}$. Research of Mgbased alloy used as biodegradable mechanical materials has been a hot spot ${ }^{3}$. The key obstacle of the bio-absorbable $\mathrm{Mg}$ implants is their rapid degradation which results in hydrogen evolution, serious local alkalization and lost of their original strengths before the healing of bone tissues ${ }^{4}$.

Many kinds of protective coatings have been prepared to control the degradation of $\mathrm{Mg}$ and $\mathrm{Mg}$-based alloys effectively. Most of the reported work was related with the coating effect on the corrosion $^{5-7)}$ and biological properties ${ }^{8-12)}$ of $\mathrm{Mg}$ and $\mathrm{Mg}$-based alloys. However, the influence of the coatings on the mechanical behavior of $\mathrm{Mg}$ and Mg-based alloys in dynamic simulated body fluids was limited. Thus, mechanical characteristics of $\mathrm{Mg}$ alloys in dynamic simulated body fluids during degradation should be enhanced since implants generally serve under conditions of stress corrosion. The purpose of the present work is to evaluate the Sicontained coating effect on the tensile properties of AZ31B Mg alloy in dynamic simulated body fluid.

\section{Materials and Methods}

Samples used for in vitro mechanical evaluation were the uncoated extruded AZ31B Mg alloy (wt.\%: Al 3\%; Zn 1\%; Mg, Correspondence to: Dr. Qiang Wang, School of Stomatology, China Medical University, Nan Jing North Street 117\#, Shenyang 110002 , China;Tel: +862422891690; E-mail: mfqwang@yahoo.com.cn remaining Gmanufactured by Institute of Metal Research, Chinese Academy of Sciences) and the alloy with a Si-containing coating. The cross-section morphology of the coating was examined by using Hitachi S-3400N scanning electron microscopy (SEM-EDX). The chemical structure of the coatings formed on the alloys was analyzed by means of X-ray photoelectron spectrometry (XPS, Escalab250, Thermo Corp., USA).

The samples were processed into standard samples along the longitudinal dimension for the tensile test, shown in Fig. 1a with gauge dimensions of $56 \mathrm{~mm}$ (length) and $5 \mathrm{~mm}$ (diameter). For the fabrication of Si-containing coating, the alloy samples were etched in a mixed acid solution of oxalic acid and acetic acid at room temperature for surface activation, and subsequently immersed in an electrolyte solution, a mixing solution of $\mathrm{NaOH}$, $\mathrm{Na}_{2} \mathrm{SiO}_{3}$ and $\mathrm{Na}_{4} \mathrm{P}_{2} \mathrm{O}_{7}$ for 120 hours at $60{ }^{\circ} \mathrm{C}$, then dried at $40^{\circ} \mathrm{C}$. The effect of Si contained coating on the mechanical integrity of the extruded AZ31B Mg alloy was studied by constant extension rate tensile method in Hank's solution at $37 \pm 0.5^{\circ} \mathrm{C}$ using a universal testing machine (SANS 30t, China). The composition of Hank's solution is as follows: $\mathrm{NaCl} 8 \mathrm{~g} / \mathrm{L}, \mathrm{KCl} 0.40 \mathrm{~g} / \mathrm{L}$, $\mathrm{MgSO}_{4} \cdot 7 \mathrm{H}_{2} \mathrm{O} 0.10 \mathrm{~g} / \mathrm{L}, \mathrm{MgCl}_{2} \cdot 6 \mathrm{H}_{2} \mathrm{O} 0.10 \mathrm{~g} / \mathrm{L}, \mathrm{CaCl}_{2} 0.14 \mathrm{~g} / \mathrm{L}$, $\mathrm{Na}_{2} \mathrm{HPO}_{4} \cdot 2 \mathrm{H}_{2} \mathrm{O} 0.12 \mathrm{~g} / \mathrm{L}, \mathrm{KH}_{2} \mathrm{PO}_{4} 0.06 \mathrm{~g} / \mathrm{L}, \mathrm{NaHCO}_{3} 0.35 \mathrm{~g} / \mathrm{L}$, glucose $1 \mathrm{~g} / \mathrm{L}$.

The schematic diagram of the experimental set-up is shown in Fig. $1 \mathrm{~b}$. The volume of the solution container is $2.5 \mathrm{~L}$ circulated by a pump with a cycle speed of about $13 \mathrm{~mL} / \mathrm{sec}$. The temperature of the Hank's solution was maintained at $37 \pm 0.5{ }^{\circ} \mathrm{C}$ during the 
(a)

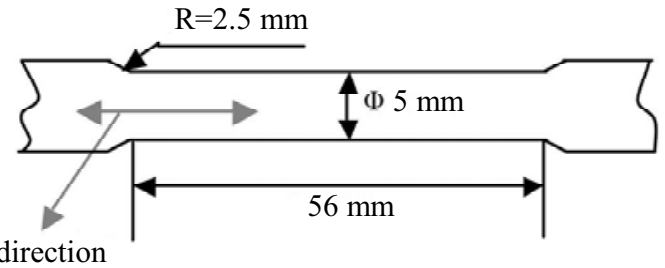

(b)

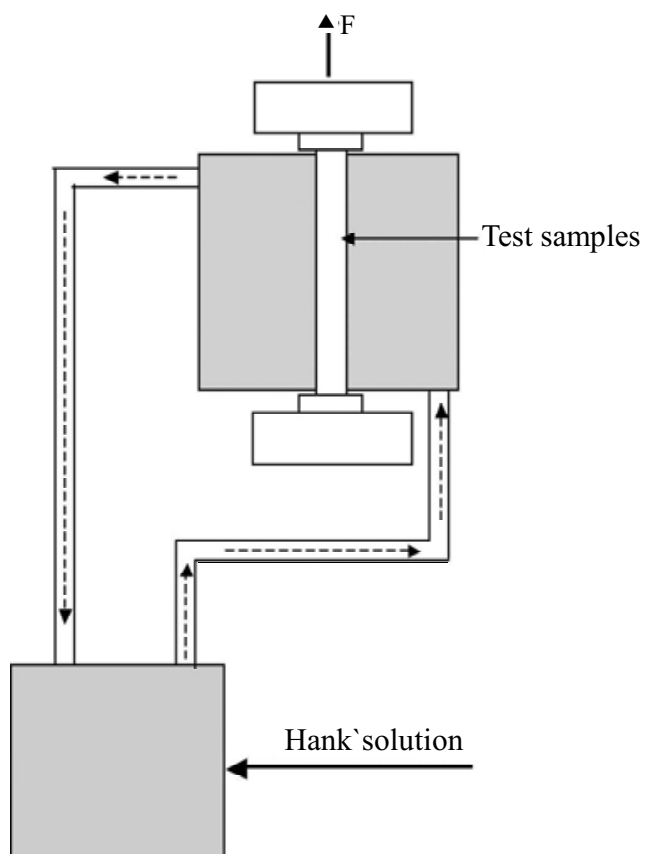

Figure 1. (a) Schematic diagram of the specimens; (b) Schematic diagram of the experimental set-up to evaluate the mechanical integrity of the alloy samples in Hank's solution at $37 \pm 0.5^{\circ} \mathrm{C}$

experiments. The tensile test samples were pulled at a cross-head speed of $0.05 \mathrm{~mm} / \mathrm{min}$ until fracture. For comparison, tension of uncoated AZ31B Mg alloy was also carried out in air at the same cross-head speed. The ultimate tensile strength (UTS) and time of fracture (TOF) obtained from tensile were used to evaluate the mechanical properties of the AZ31B Mg alloy. An average of 4 specimens in each group, i.e. uncoated, coated was tested for each experimental condition. After the completion of the tests, the fracture surfaces were ultrasonically rinsed in alcohol for about $15 \mathrm{sec}$, dried in the air and then examined using a scanning electron microscope (SEM).

\section{Results}

\section{Morphology and chemical composition of the coating}

The cross-section morphology of Si-containing coating (Fig. 2a) shows that the coating thickness is about 3-5 $\mu \mathrm{m}$. Fig. $2 \mathrm{~b}$, Fig. 2c and Fig. 2d show the XPS spectra of the coated alloy. It can be found that the coating is consisted of $\mathrm{Mg}_{2} \mathrm{SiO}_{4}, \mathrm{MgO}$ and $\mathrm{SiO}_{2}$.

\section{Tensile test}
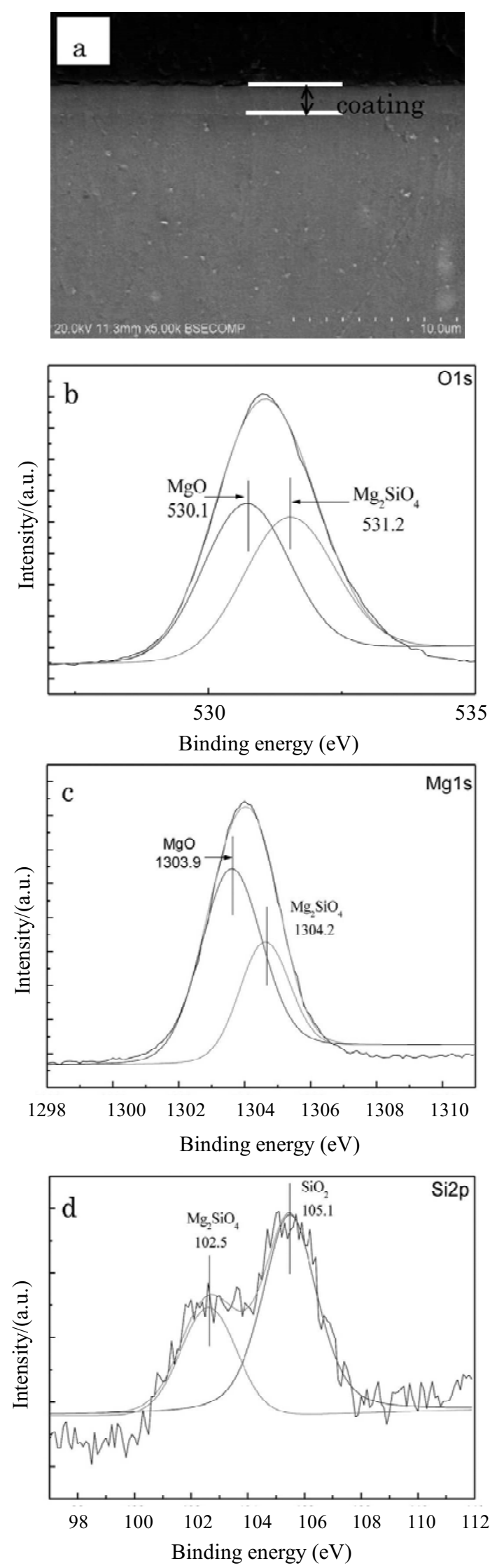

Figure 2. SEM morphologies of the cross-section and XPS spectra of the Si-containing coating 
Qiang Wang et.al.: Constant Extension Rate Tensile in the Dynamic Simulated Body Fluid

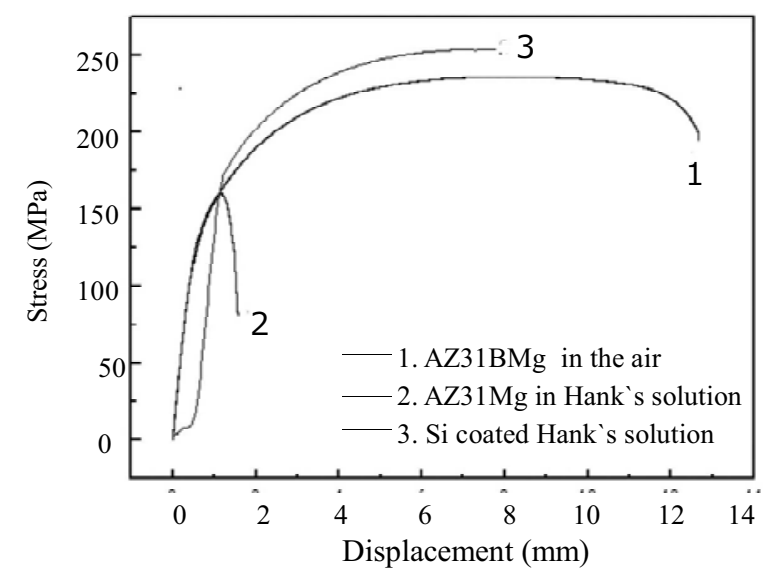

Figure 3. The constant extension rate test results

The constant extension rate test results for the samples in the air and Hank's solution were shown in Fig. 3. In the stressdisplacement curve of the AZ31B Mg alloy in the air, the stress increased slightly with the increasing of the strain, displaying that the extruded alloy did not show a work-hardening property. It can be found that as the stress was larger than UTS, necking phenomenon occurred. The stress was decreased until fracture of the alloy. However, no significant necking phenomenon happened
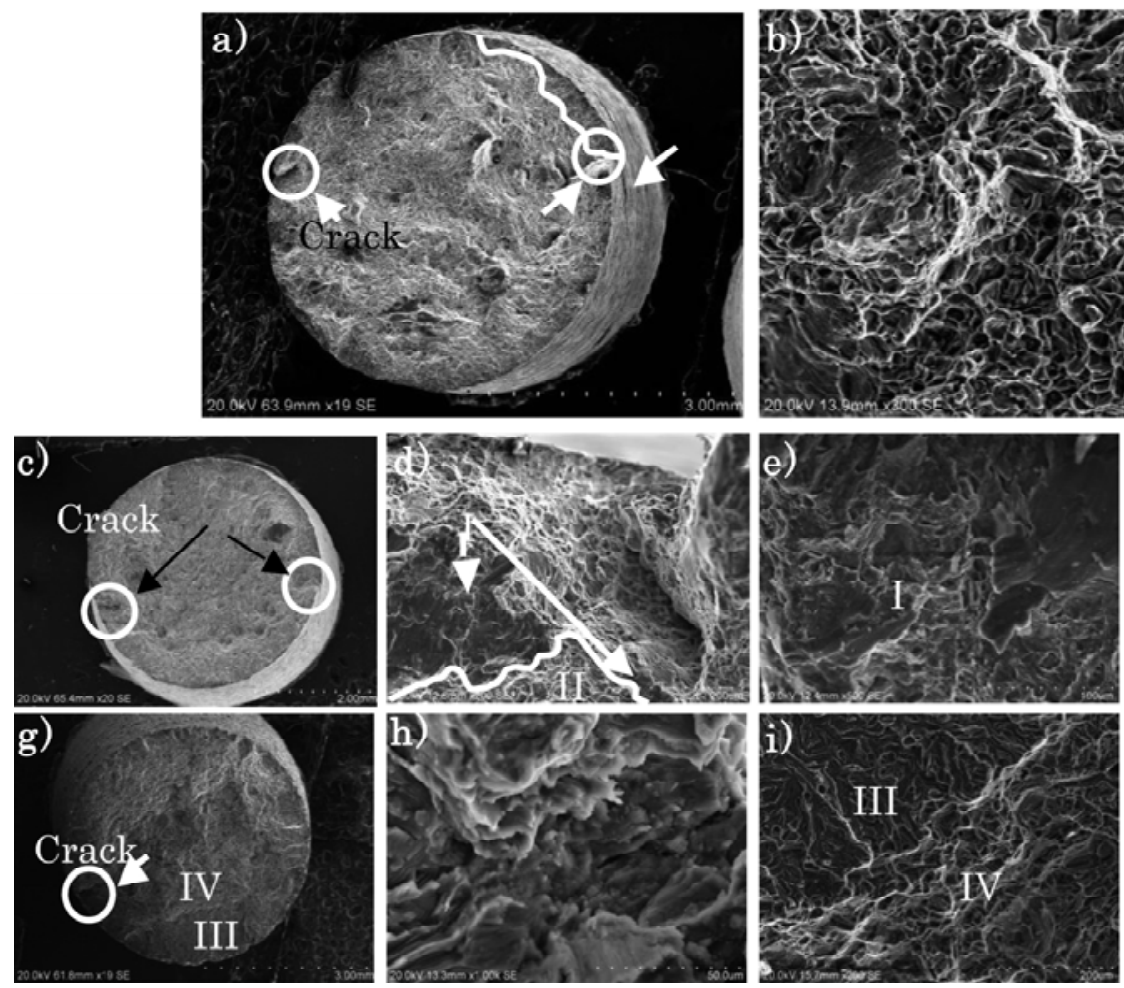

for the uncoated in Hank's solution. After the stress reached a peak rapidly, the alloy fractured immediately. As for the coated alloy in Hank's solution, the curve trend was almost the same to the uncoated alloy in the air before the stress reached a peak.

The UTS of the uncoated alloy is about $232 \pm 3.5 \mathrm{MPa}$ while that of the same alloy in Hank's alloy was only $168 \pm 11.3 \mathrm{MPa}$. The samples underwent a loss of about $28 \%$ in its strength. The UTS of the coated alloy in Hank's alloy was about $245 \pm 10.6 \mathrm{MPa}$, somewhat higher than the samples in the air resulting from the contribution of the coating. The time to failure of the uncoated alloy in the air, the uncoated alloy in Hank's solution and the coated alloy in Hank's solution were $242 \pm 16.3 \mathrm{~min}, 32.1 \pm 6.4 \mathrm{~min}$ and $155.7 \pm 14.5 \mathrm{~min}$, respectively. Section shrinkage of the uncoated alloy in Hank's solution was about $4.0 \%$ while the coated alloy in Hank's alloy was about $23.6 \%$ close to the uncoated alloy in the air $26.0 \%$.

\section{SEM of tensile fractography}

Typical fracture surface of the samples tested in the air are shown in Fig. 4. The fracture surface of AZ31B Mg alloy in air shows dominant ductile nature of failure (Fig. 4a). The crack initiation zone and the crack propagation path are marked by circle and arrow respectively. Higher-magnification fracture view of

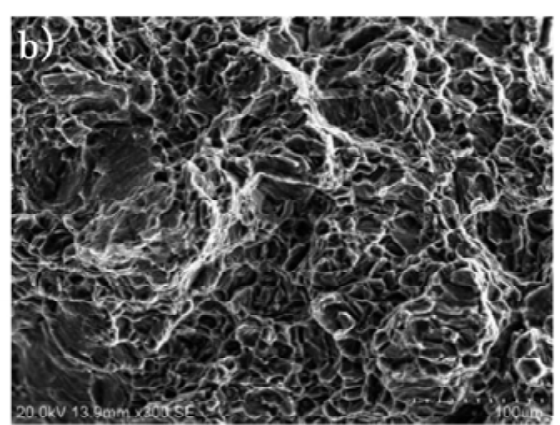

Figure 4. SEM fractographs of the uncoated and coated AZ31B Mg alloy tested in the air and Hank's solution at $37 \pm 0.5{ }^{\circ} \mathrm{C}$ : a) overall view of the uncoated in the air; b) higher-magnification view of the uncoated in the air; c) overall view of the uncoated in Hank's solution; d) edge of the uncoated in Hank's solution revealing crack initiation and propagation; e) Higher-magnification of I zone in d); f) Higher-magnification of II zone in d); g) overall view of the coated in Hank's solution; h) edge of the coated in Hank's solution revealing crack initiation and propagation; i) Higher-magnification of III and IV zone in g); j) Higher-magnification of IV zone in i). Curve in d) is the boundary of zone I and zone II. 

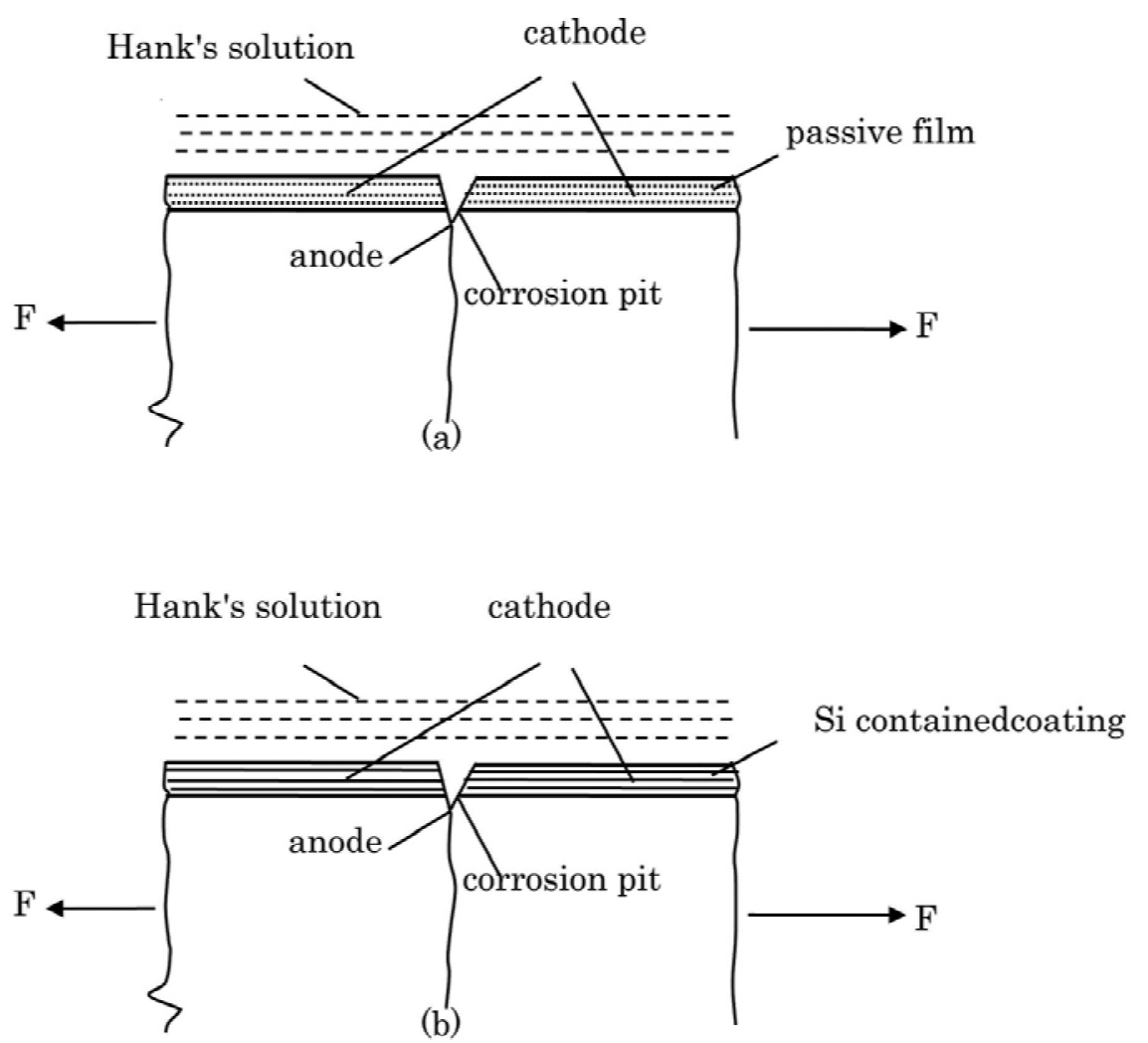

Figure 5. Corrosion mechanism of the uncoated and coated alloy under constant extension rate tensile in Hank's solution. The passive film on the AZ31B Mg alloy is not stable and galvanic corrosion is more serious resulting in rapid local corrosion

AZ31B Mg alloy shown in Fig. 4b in air displays a mixed intergranular and transgranular mode with intergranular failure being predominant.

The macrographs of the fractured AZ31B Mg alloy samples tested in Hank's solution showed that AZ31B Mg alloy had undergone general and localized corrosion (Fig. 4c-4f). The edge of the fracture surface (Fig. 4e) showed typical transgranular cleavage. The fracture surface of AZ31B Mg alloy sample shown in Fig. 4d revealed mixed transgranular (zone I) and intergranular (zone II) fracture, though some transgranular failure existed, divided by the curve. No evidence of corrosion associated with the grain boundaries was found. The failure of the AZ31B Mg alloy samples tested in Hank's solution is attributed to the formation of the corrosion pit, which is visible in the crack initiation region on the sample surface (Fig. 4c arrow).

The fracture surface of coated samples in Hank's solution is shown in Fig 4.g-j. The fracture surface of the coated AZ31B Mg samples tested in the same corrosive environment was different compared to that of the uncoated under the same test conditions. The fracture surface of the coated samples shows three distinct regions. One zone represents the crack initiation site marked by the arrow in Fig. 4g. Higher magnification of the region shown in Fig. $4 \mathrm{~h}$ reveals that the fracture surface is covered with corrosion products, suggesting that anodic dissolution occurs remarkably. There had been significant corrosion along grain boundaries. An obvious boundary existed between the other two zones (zone III, IV) shown in Fig. 4i. The failure of Zone III is predominantly transgranular type. The fracture surface in the zone IV reveals ductile features exhibiting small dimples. It was suggested that Ca-P coating delayed the crack initiation caused by pitting corrosion.

\section{Discussion}

The successful applications of Mg-based alloys as degradable orthopaedic implants are mainly inhibited due to their high degradation rates in physiological environment and consequent loss in the mechanical integrity ${ }^{13}$. In 2010, slow strain rate tensile in static Kokubo's simulated body fluid (SBF) indicated that coating could inhibit the mechanical loss of the Mg-Zn-Ca alloy ${ }^{14)}$. However, the tensile fractography and the fracture mechanism were not discussed in the above literature. In the present study, the tensile properties of the coated alloy increased by about $385 \%$ (for TOF), $45.8 \%$ (for UTS) and $493 \%$ (for section shrinkage) when tested in Hank's solution compared with the uncoated. Sicontained coating delays the decrease in strength of AZ31B Mg alloy which is helpful for a longer service time.

It can be found in the typical fracture surface of the uncoated 
Qiang Wang et.al.: Constant Extension Rate Tensile in the Dynamic Simulated Body Fluid

samples in the air, some localized areas showed a brittle appearance. These areas might correspond to fracture associated with $\beta$-phase particles ${ }^{15)}$. The fracture features of AZ31B Mg alloy in the air are similar to that of AZ80 alloy and ZE41 alloy in air reported by M.Booby Kannan et $\mathrm{al}^{16)}$. The fracture surface feature in Hank's solution of the coated AZ31B Mg alloy is different with the uncoated. The uncoated alloy exhibited predominant intergranular cracks while the coated revealed mixed intergranular and transgranular mode failure.

The corrosion mechanism of the uncoated and coated alloy under constant extension rate tensile in Hank's solution was displayed in Fig. 5. Based on the fracture surface analysis, it is suggested that the fracture path observed in $\mathrm{AZ31B} \mathrm{Mg}$ alloy in Hank's solution is consistent with a mechanism involving anodic dissolution and hydrogen. During the tensile test, passive film formed on the AZ31B Mg alloy. However, the passive film on the $\mathrm{AZ31B} \mathrm{Mg}$ alloy is not stable and galvanic corrosion is more serious resulting in rapid local corrosion. On the other hand, micro cell reaction also occurred on the surface of the uncoated alloy because of the composition difference on different area of the alloy. The anode area of the micro cell is more easily destroyed in the Hank's solution. As for the coated alloy, the surface was covered by the ceramic coating which provided effective protection for the substrate. When the coating was peeled off under mechanical stress, the substrate was exposed to the Hank's solution and local corrosion occurred. However, because the substrate elsewhere was coated, little galvanic corrosion occurred, which was one of the critical factors accelerating the failure of $\mathrm{Mg}$-based alloys in the electrolyte environment.

\section{Acknowledgements}

This study was financially supported by funds from National Basic Research Program of China (No. 2012CB619101) and a grant from Chinese Academy of Sciences (No. KGCX2-YW-207).

\section{References}

1. Tschegg EK, Lindtner RA, Doblhoff-Dier V, Stanzl-Tschegg SE, Holzlechner G, Castellani C, Imwinkelried T and Weinberg A. J Mech Behav Biomed Mater 4: 766-775, 2011

2. Wang Q, Tan L L, Xu W L, Zhang B C and Yang K. Dynamic behaviors of a Ca-P coated AZ31B magnesium alloy during in vitro and in vivo degradations. Mater Sci Eng B-Adv 176: 1718-1726, 2011

3. Liu B, Zheng Y F and Ruan Liquan. In vitro investigation of Fe30Mn6Si alloy as potential biodegradable metallic material. Mater Lett 65: 540-543, 2011

4. Mark P S, Alexis M P, Jerawala H and George D. Magnesium and its alloys as orthopedic biomaterials: A review. Biomaterials 27: 1728-1734, 2006
5. Song Y W, Shan D Y and Han E H. Electrodeposition of hydroxyapatite coating on AZ91D magnesium alloy for biomaterial application. Mater Lett 62: 3276-3279, 2008

6. Witte F, Fischer J, Nellesen J, Crostack H-A, Kaese V, Pisch $\mathrm{A}$, Beckmann $\mathrm{F}$ and Windhagen $\mathrm{H}$. In vitro and in vivo corrosion measurements of magnesium alloys. Biomaterials 27: 1013-1018, 2006

7. $\mathrm{Mu} \mathrm{W} Y$ and Han Y. Characterization and properties of the $\mathrm{MgF}_{2} / \mathrm{ZrO}_{2}$ composite coatings on magnesium prepared by micro-arc oxidation. Surf Coat Technol 202: 4278-4284, 2008

8. Xu L P, Pan F, Yu G N, Yang L, Zhang E L and Yang K. In vitro and in vivo evaluation of the surface bioactivity of a calcium phosphate coated magnesium alloy. Biomaterials 30 : 1512-1523, 2009

9. Song Y, Zhang S X, Li J N, Zhao C L and Zhang X N. Electrodeposition of Ca-P coatings on biodegradable $\mathrm{Mg}$ alloy: In vitro biomineralization behavior. Acta Biomater 6: 1736-1742, 2010

10. Du H, Wei Z J, Wang H W, Zhang E L, Zuo L and Du L P. Surface microstructure and cell compatibility of calcium silicate and calcium phosphate composite coatings on $\mathrm{Mg}$ $\mathrm{Zn}-\mathrm{Mn}$-Ca alloys for biomedical application. Colloids Surf B Biointerfaces 83: 96-102, 2011

11. Gao J C, Qiao L Y, Li L C and Wang Y. Hemolysis effect and calcium-phosphate precipitation of heat-organic-film treated magnesium. Trans Nonferrous Met Soc China 16: 539-544, 2006

12. Jun Yen Uan, Jun Kai Lin, Sun Y S, Yang W E, Chen L K and Huang $\mathrm{H} \mathrm{H}$. Surface coatings for improving the corrosion resistance and cell adhesion of AZ91D magnesium alloy through environmentally clean methods. Thin Solid Films 518: 7563-7567, 2010

13. Bobby Kannan M, Raman R.K. Singh. In vitro degradation and mechanical integrity of calcium-containing magnesium alloys in modified-simulated body fluid. Biomaterials 29 : 2306-2314, 2008

14. Wang H X, Guan S K, Wang X, Ren C X and Wang L G. In vitro degradation and mechanical integrity of $\mathrm{Mg}-\mathrm{Zn}-\mathrm{Ca}$ alloy coated with $\mathrm{Ca}$-deficient hydroxyapatite by the pulse electrodeposition process. Acta Biomater 6: 1743-1748, 2010

15. Bobby Kannan M, Dietzel W, Blawert C, Riekehr S and Koçak M. Stress corrosion cracking behavior of Nd:YAG laser butt welded AZ31 Mg sheet. Mater Sci Eng A 444: 220-226, 2007

16. Bobby Kannan M, Dietzel W, Blawert C, Atrens B A and Lyon P. Stress corrosion cracking of rare-earth containing magnesium alloys ZE41, QE22 and Elektron 21 (EV31A) compared with AZ80. Mater Sci Eng A: 529-539, 2008 
J.Hard Tissue Biology Vol. 22(2):177-182, 2013 